http:// bjas.bu.edu.eg

\title{
Optimizing the Biofuel Production by Hydrotreating Jojoba Oil S.A.El-khatib ${ }^{1}$, S.A.hanafi ${ }^{1}$,M.M.H.Arief ${ }^{2}$ and E.F.Al-amrousi ${ }^{I}$ \\ ${ }^{I}$ Egyptian Petroleum Research Institute, Nasr City, Cairo, Egypt \\ ${ }^{2}$ Faculty of Science, Benha Univ., Benha, Egypt \\ E-Mail: selkhatib43@gmail.com
}

\section{Abstract}

Hydroprocessing of vegetable oils is a prominent technology that using the existing infrastructure of petroleum refineries, for producing environmental friendly and high quality transportation fuel.

In this study, Jojoba oil was hydrotreated, using the conventional $\mathrm{Ni} \mathrm{Mo} / \mathrm{Al}_{2} \mathrm{O}_{3}$ catalyst in the sulfided form .A series of experiments were performed at various conditions in a cata -test unit, to predict the influence of reaction temperature, pressure and liquid hourly space velocity on the yield and quality of the obtained product . The results indicated that hydrotreating process is much more selective for producing hydrocarbons in the gas oil range.

$450^{0} \mathrm{C}, 2.5 \mathrm{MPa}$ and $5 \mathrm{~h}^{-1}$ LHSV were found to be the optimum conditions that generate $84.1 \mathrm{wt} \%$ biofule with a selectivity of $88.37 \%$. These results were confirmed via various analyses such GC, FTIR, ASTM...etc. The hydrotreated product obtained at the best operating conditions was evaluated and reflects the significant improvement of the physicochemical properties of the biofuel attained compared with those of the crude jojoba oil.

Keywords: Green Fuel, Hydrotreated, Jojoba Oil

\section{Introduction}

In the context of gradual depletion of fossil fuels reserves, and increasing energy demand with ever increasing number of vehicles employing compression ignition engines, makes the implementation of sustainable fuels a crucial issue worldwide [1-2]. Many alternatives that can be derived from sources other than petroleum crude oil have been considered [3]. Among these, biofuels, that received a great attention as an alternative, since it contains no sulfur, nontoxic, biodegradable and renewable fuel.

Recently, there are several studies on the production of biofuel from utilization of biomass substrates, waste oil, vegetable oils and animal fats, ....etc, that can serve as a partial substitute for fossil fuels [4-8].

Plant oils, such as sunflower, corn, rapeseed, palm oils ...etc, can be visualized as a promising sources for biofuel production [9-11]. Consequently, the demand of this type of oils is expected to noticeably increase in the next few years. However, the intensive use of biofuels come from vegetable oils could derive in a shortage of raw materials for feed purposes and a steep rise of food price. This situation could be avoided by the use of less valuable feedstocks such as waste cooking oils or non - edible oils [12-14]. In this investigation the non- edible oil extracted from jojoba seeds has been chosen and evaluated as an appropriate feedstock for biofuel obtainment.

The most commonly used method for biofuel, particularly biodesel production, is the transestrification of triglycerides with an alcohol (methanol / ethanol) using basic or acid catalysts, producing glycerol as a secondary product [15-18]. Nevertheless, vegetable oils can also be converted to liquid hydrocarbon fuels using catalytic technology [19-21] such as cracking and hydroprocessing techniques that regarded as the most reasonable and promising technologies for high yield of liquid products .

The objective of the present research is to optimize the process operating conditions for the production of petroleum-like fraction (particularly biodiesel) from jojoba oil via hydrotreating technology using $\mathrm{Ni} \mathrm{Mo} / \mathrm{Al}_{2} \mathrm{O}_{3}$ catalyst.

\section{Materials and methods}

\subsection{Feedstock}

Jojoba oil purchased from Egyptian Company for Natural Oil has been used as a feedstock.

\subsection{Catalyst preparation}

In this study, the conventional hydrotreating $\mathrm{Ni}$ $\mathrm{Mo} / \mathrm{Al}_{2} \mathrm{O}_{3}$ catalyst (HR-348) procatalyse $\mathrm{Co}$, was employed. The catalyst was calcined at $400{ }^{\circ} \mathrm{C}$ for 6 hrs, and then presulfided with 2 wt \% dimethyl disulfide (DMDS) in $\mathrm{n}$ - hexane mixture. Sulfidation was performed at 2 different temperatures. The first sulfidation has done at $260{ }^{\circ} \mathrm{C}$ for $3 \mathrm{hrs}$ and the second was carried out at $360{ }^{\circ} \mathrm{C}$ also for $3 \mathrm{hrs}$.

\subsection{Catalytic activity measurements}

Hydrotreatment of jojoba oil was processed using a continuous high pressure micro-reactor (cata-test unit). A detailed description of the apparatus was given elsewhere [22]. The sulfided $\mathrm{Ni} \mathrm{Mo} / \mathrm{Al}_{2} \mathrm{O}_{3}$ catalyst mixed with the same volume of ceramic, was loaded in the middle zone of a stainless steal tubular reactor $(1.9 \mathrm{~cm}$ i.d. and $50 \mathrm{~cm}$ in length), equipped with electric heating. $\mathrm{H}_{2}$ gas was supplied to the unit from a $\mathrm{H}_{2}$ cylinder, while liquid feed was pumped at the top of the reactor by means of a piston pump having an adjusting knob. The experiments were accomplished at reaction temperatures in the range of 
375- $500{ }^{\circ} \mathrm{C}$, and LHSV of $1-5 \mathrm{~h}^{-1}$ under $\mathrm{H}_{2}$ pressures of $1-5 \mathrm{MPa}$.

The effluent gases and liquids were collected and estimated. The organic fraction, separated from water that involved in the liquid product, were analyzed according to the different ASTM method : Density ( D- 287 ), kinematic viscosity ( D- 455), sulfur content ( D-4294), using X- ray fluorescence sulfur meter, ASTM distillation ( D -86 ). More evaluation for the virgin oil and the hydrotreated organic product, obtained at $450{ }^{0} \mathrm{C}$, LHSV of $5 \mathrm{~h}^{-1}$ and $2.5 \mathrm{MPa} \mathrm{H}_{2}$ pressure, were carried out, including the determination of pour point (D-97), molecular weight (D-2502), calorific value (D-240), refractive index (D-1747), ash content (D- 482) and flash point (D-92), beside the analyses via GC and FTIR technique. The gas chromatographic apparatus, Agilent 6890, equipped with flame ionization detector (FID) has been employed. Separations were performed on HP-1 column with 30 meter length and $0.25 \mathrm{~mm}$ ID. The temperature of the injector and detector were set at $300{ }^{\circ} \mathrm{C}$. FTIR spectroscopy was determined using Nicoletis- LOFT-IR Nicolet 15-10.

\section{Results and discussion}

\subsection{Effect of reaction temperature}

To optimize the operating conditions for the hydrotreating process to produce liquid biofuel from jojoba oil several approaches have to be examined. Reactor temperature is visualized as one of the most significant parameter affecting the catalyst performance. Therefore, the influence of this factor on the quality and quantity of the hydrotreated jojoba oil has been explored.

The present study took place at four different reaction temperatures, in the range of $375-500{ }^{\circ} \mathrm{C}$, at constant experimental conditions i.e. $\left(5 \mathrm{~h}^{-1} \mathrm{LHSV}, 2.5\right.$ $\mathrm{MPa}$ hydrogen pressure and $1600 \mathrm{~L} / \mathrm{L} \mathrm{H}_{2} /$ feed ratio), using sulfided $\mathrm{Ni} \mathrm{Mo} / \mathrm{Al}_{2} \mathrm{O}_{3}$ catalyst. The obtained results are declared in Table 1 . The reported data reflect a sharp increase in the converted yield from 48.81 to $85.59 \mathrm{wt} \%$, particularly upon raising the reactor temperature from $375^{\circ} \mathrm{C}$ up to $400^{\circ} \mathrm{C}$, beyond which the total conversion is considerably improved to attain a value of $95.23 \mathrm{wt} \%$ at $450^{\circ} \mathrm{C}$. At more elevated temperatures, i.e. $500^{\circ} \mathrm{C}$, the influence of this factor on the amount of the transformed feed become insignificant. It worth mentioning that we found difficulties for carrying out the experiments at temperatures below $375^{\circ} \mathrm{C}$ due to the transformation of the products to waxy constituents that cannot be easily collected and makes some troubles to the apparatus used. This phenomenon may be ascribed to the hydrogenation of the double bonds involved in the structure of jojoba molecules, forming saturated oil that cannot be easily fragmented, since such low temperature applied is not enough to promote the disconnection between their bonds.
Table 1 shows also that, moderate amounts of the effluent gases resulted from the hydrotreating process, comprised $6.47-11.64 \mathrm{wt} \%$, were observed throughout the whole range of temperature applied. Although the high temperatures suit the procession of hydrocracking reaction due to its endothermicity, however, the formation of gases and light fractions are not so intensive here since the used $\mathrm{Ni} \mathrm{Mo} / \mathrm{Al}_{2} \mathrm{O}_{3}$ catalyst has not enough strong acid sites to promote a server cracking of molecules, compared to other acidic catalyst such as zeolite as an example.

Nevertheless, somewhat enhancement of gas formation with temperature accompanied by slight diminutions of the liquid yield (which composed mainly from organic and some aqueous components) could be observed. After separating the oil from the contaminated water, involved in the liquid yield, it could be noticed that, the products achieved at higher reaction temperatures include relatively more water, on the account of the oil content, than those obtained at lower temperatures. This may be attributed to enhancement of the rate of dehydration reaction which is more favored at elevated temperatures.

Distinct drops in both density and kinematic viscosity of the produced oil are realized with exceeding the reaction temperature, due to the procession of hydrotreating that accompanied by hydrocracking reaction.

To determine the boiling range distribution of the organic liquid products which accomplished at various reaction temperatures, ASTM distillation has been implemented and the accessible data were also depicted in Table1. The conversion to biofuel is considered to be the amount of distillates possessing a lower boiling point than that of the crude jojoba oil which has been determined here and found to be > $323^{0} \mathrm{C}$.

It is obvious from the ASTM results that unsatisfactory transformation to petroleum-like fractions, not exceed than 45 vol \% of the produced oil has been achieved at $350^{\circ} \mathrm{C}$. The remainder represents unconverted oil, residue and losses. At higher temperatures, substantial quantities of the required products ranging from 85 to 97 vol \% were accomplished. Therefore, the recommended reaction temperature to be applied in hydrotreating jojoba oil is $450{ }^{\circ} \mathrm{C}$, in order to acquire the highest activity with good selectivity to biofuel production.

Moreover, the biofuel obtained at various reaction temperatures were fractionated and separated to three portions according to their boiling ranges, i.e. (IBP$\left.150{ }^{0} \mathrm{C}\right),\left(150-250{ }^{0} \mathrm{C}\right)$ and $\left(250-323^{\circ} \mathrm{C}\right)$, for gasoline kerosene and gas oil, respectively. Generally, it could be noticed that reaction temperature has some influence on the percentages of each of the forementioned fractions which involved in the distillates under investigation. As evidenced from Fig (1) that diesel - like fraction is the most 
prevalence distillate particularly at 400 and $450{ }^{\circ} \mathrm{C}$ that comprised $55 \mathrm{vol} \%$ of the biofuel acquired.

Table (1|) Distribution of the Hydrotreated Products Obtained at Various Temperatures Pressure: $2.5 \mathrm{MPa}$,

\begin{tabular}{|c|c|c|c|c|}
\hline Hydrotreated Products & $375^{0} \mathrm{C}$ & $400^{0} \mathrm{C}$ & $450{ }^{0} \mathrm{C}$ & $500{ }^{0} \mathrm{C}$ \\
\hline Total conversion, wt \% & 48.805 & 85.587 & 95.23 & 96.88 \\
\hline \multicolumn{5}{|l|}{ Hydrotreated product, Wt \% } \\
\hline Gases & 6.47 & 7.46 & 7.51 & 11.64 \\
\hline Liquid & 93.53 & 92.54 & 92.49 & 88.36 \\
\hline Water content & 1.04 & 1.45 & 3.62 & 3.98 \\
\hline Oil content & 92.49 & 91.09 & 88.87 & 84.38 \\
\hline Density at $20{ }^{\circ} \mathrm{C}$ & 0.8595 & 0.820 & 0.8065 & 0.7017 \\
\hline Kinematic viscosity at $40{ }^{\circ} \mathrm{C}$ & 22.0679144 & 16.093376 & 3.695354 & 1.925515 \\
\hline Sulfur content, ppm & 0.007 & 0.006 & 0.006 & 0.003 \\
\hline \multicolumn{5}{|l|}{ ASTM distillation, vol. $\% /{ }^{0} \mathrm{C}$} \\
\hline IBP & 110 & 60 & 60 & 60 \\
\hline 10 & 110 & 100 & 100 & 100 \\
\hline 20 & 258 & 160 & 155 & 120 \\
\hline 30 & 303 & 199.8 & 179.8 & 150 \\
\hline 40 & 313.7 & 250.6 & 231.8 & 199.8 \\
\hline 50 & 324.4 & 284.4 & 256.6 & 231.6 \\
\hline 60 & 324.4 & 284.4 & 252.7 & 231.6 \\
\hline 70 & 324.4 & 284.4 & 284.4 & 284.4 \\
\hline 80 & 324.4 & 305.3 & 305.4 & 284.4 \\
\hline 90 & 324.4 & 325.9 & 305.4 & 294.9 \\
\hline FBP & 324.4 & 325.9 & 305.4 & 294.9 \\
\hline Biofuel recovered, vol. \% & 45 & 85 & 95 & 97 \\
\hline Unconverted, residue, and Loss, vol. \% & 55 & 15 & 5 & 3 \\
\hline Biofuel yield, wt \% based on feed & 41.295 & 76.68 & 84.1 & 81.26 \\
\hline Biofuel selectivity , \% & 84.61 & 89.589 & 88.37 & 83.87 \\
\hline
\end{tabular}

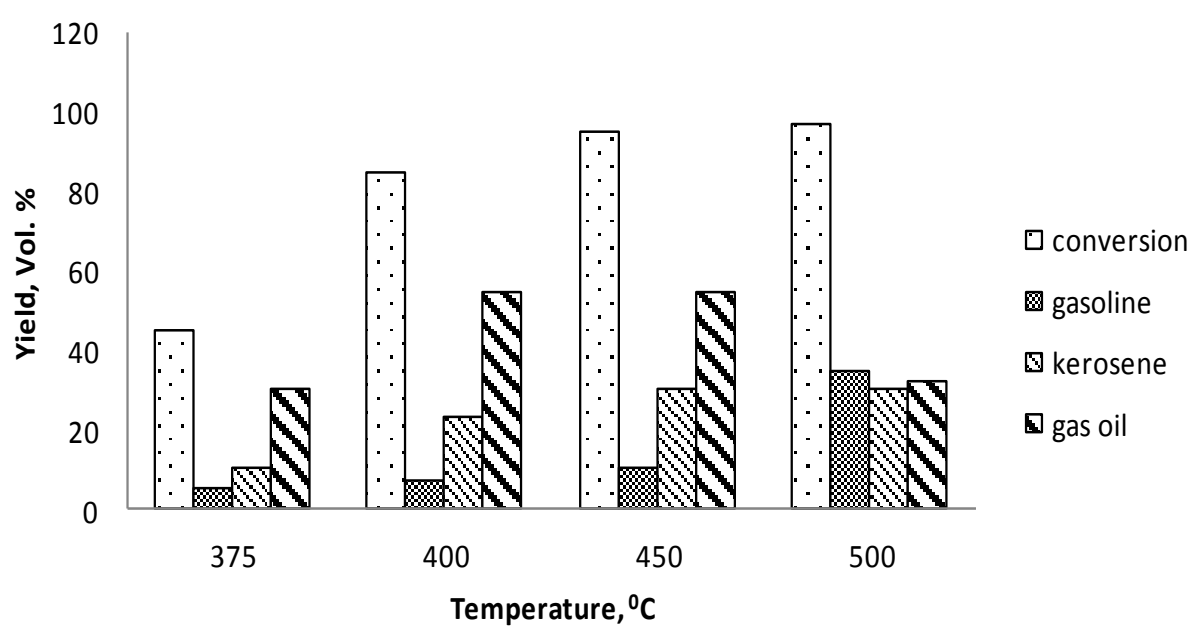

Fig (1) Distribution of the individual fractions of the biofuel obtained as a function of Temperature.

3.2 Effect of liquid hourly space velocity (lhsv)

Jojoba oil was hydrotreated at $450^{\circ} \mathrm{C}, 2.5 \mathrm{MPa}$ hydrogen pressure and various liquid hourly space velocities (LHSV), in order to examine the effect of this parameter on the yield and quality of the produced constituents.

The data represented in Table 2 reveals a slight enhancement of the total conversion as the LHSV 
increased from $1 \mathrm{~h}^{-1}$ to $2.5 \mathrm{~h}^{-1}$, beyond which a significant improvement has been achieved. A considerable influence of space velocities on the distribution of the products can be observed.

At lower LHSV (i.e. $1 \mathrm{~h}^{-1}$ ), substantial amount of gases comprised around $30 \mathrm{wt} \%$ was released, which can not be considered, in this work, as a biofuel product. Simultaneously, low yield (amount to $66.16 \mathrm{wt} \%$ ) of oil was produced compared to 83.25 and $88.87 \mathrm{wt} \%$ that accomplished at higher space velocities. Undoubtedly, this ascribed to the development of cracking process that favored with increasing the contact time.

It could be recognized that, the product obtained at LHSV of $1 \mathrm{~h}^{-1}$ constitutes mainly from appreciable amount of gases contaminated with high boiling point liquid. This could be explained in terms that sever cracking took place at such suitable conditions of high temperature and long contact time, leading to formation of gases and light olefinic compounds followed by fast polymerization of most of these unsaturated fragments giving rise to fraction with high boiling points.

Generally, the reaction products exhibit perfect values of density and kinematic viscosity, particularly for these performed at relatively higher LHSV; also the data indicate the absence of sulfur.

According to the ASTM results (Table2), a distinct amelioration in both the yield and biofuel selectivity has been accomplished as the LHSV increased above $1 \mathrm{~h}^{-1}$, remembering that the liquid fraction with boiling point higher than $323^{\circ} \mathrm{C}$ is considered to be as unconverted oil. Although the biofuel selectivity achieved at LHSV of 2.5 and $5 \mathrm{~h}^{-1}$ are nearly similar, however, a higher yield of biofuel was attained at $5 \mathrm{~h}^{-1}$ that characterized by the predomination of fraction in the diesel range, whereas that achieved at $2.5 \mathrm{~h}^{-1}$ is distinguished by the prevalence of the middle distillate in the kerosene and diesel range associated with some polymerized components Fig (2) Therefore, $5 \mathrm{~h}^{-1}$ LHSV is recommended to carry out the further experiments.

\subsection{The effect of hydrogen pressure}

The effect of hydrogen pressure factor on the product distribution of the hydrotreated jojoba oil has been explored. Table 3 represents the results of the experiments performed at $450^{\circ} \mathrm{C}, 5 \mathrm{~h}^{-1} \mathrm{LHSV}$ and $1600 \mathrm{~L} / \mathrm{L} \mathrm{H}_{2}$ : feed, at various hydrogen pressures.

At a pressure of 1.0 $\mathrm{MPa}, 70.75 \mathrm{wt} \%$ of jojoba oil was transformed to $5.14 \mathrm{wt} \%$ gas and $94.86 \mathrm{wt} \%$ liquid products involving $3.1 \mathrm{wt} \%$ water. The gradual increase in pressure to $2.5 \mathrm{MPa}$ and after to $5 \mathrm{MPa}$, was accompanied by conspicuous improvement in the total conversion to come to the values of 95.23 and $98.15 \mathrm{wt} \%$ respectively. The data reflect also a moderate stimulation to gas formation with simultaneous drop in the oil content, as the pressure increased from 1 to $5 \mathrm{MPa}$.

Significant upgrading in both density and kinematic viscosity of the obtained oil has been occurred throughout the whole range of the pressure applied, particularly at 5MPa.

The ASTM data reported in Fig (3) reveals the unsatisfactory results shown at low hydrogen pressure. Nevertheless, upon raising the pressure up to 2.5 and $5 \mathrm{MPa}$, a sharp increase in the quantities of the aquired biofuels has been realized, at which the activity to biofuel production are nearly the same. Therefore, 2.5 $\mathrm{MPa}$ hydrogen pressure can be recommended for processing the oil, since it consumes less hydrogen, moreover, it gives better selectivity than that performed at $5 \mathrm{MPa}$.

Regarding to the distribution of the three fractions mentioned previously, the best yield of diesel fraction can be acquired at a pressure of $2.5 \mathrm{MPa}$ that amounts to $55 \mathrm{vol} \%$ of the oil product, where as the rest represent 30 vol\% kerosene, 10 vol\% in the range of gasoline and 5 vol\% unconverted oil and losses. This distribution varies at $5 \mathrm{Mpa}$, at where the amount of diesel diminished to 33 vol\% with consequent increase in gasoline to become $35 \mathrm{vol} \%$ due to cracking reaction and transformation of apart of diesel to the lighter fraction.

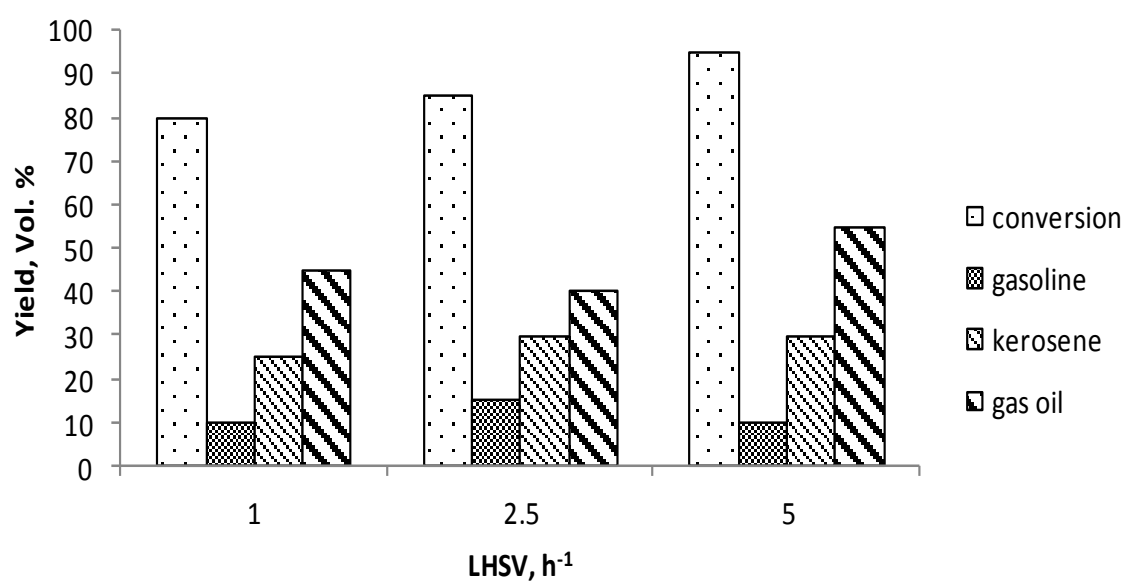

Fig (2) Distribution of the individual fractions of the biofuel obtained as a function of LHSV. 
Table (2) Distribution of the Hydrotreated Products Obtained at Various LHSV.Temperature: 450 0C, Pressure: $2.5 \mathrm{MPa}$ and $\mathrm{H} 2$ / feed: $1600 \mathrm{~L} / \mathrm{L}$

\begin{tabular}{|c|c|c|c|}
\hline Hydrotreated Products & $1 \mathrm{~h}^{-1}$ & $2.5 \mathrm{~h}^{-1}$ & $5 \mathbf{h}^{-1}$ \\
\hline Total conversion, wt \% & 85.98 & 86.665 & 95.23 \\
\hline \multicolumn{4}{|l|}{ Hydrotreated product, Wt \% } \\
\hline Gases & 29.83 & 12.88 & 7.51 \\
\hline Liquid & 70.17 & 87.12 & 92.49 \\
\hline Water content & 4.01 & 3.87 & 3.62 \\
\hline Oil content & 66.16 & 83.25 & 88.87 \\
\hline Density at $20{ }^{\circ} \mathrm{C}$ & 0.8173 & 0.8100 & 0.8065 \\
\hline Kinematic viscosity at $40{ }^{\circ} \mathrm{C}$ & 5.958485 & 4.3324092 & 3.695354 \\
\hline Sulpher content , ppm & 0.0012 & 0.0049 & 0.006 \\
\hline \multicolumn{4}{|l|}{ ASTM distillation, vol. $\% /{ }^{0} \mathrm{C}$} \\
\hline IBP & 80 & 80 & 60 \\
\hline 10 & 120 & 120 & 100 \\
\hline 20 & 205.6 & 160 & 155 \\
\hline 30 & 227.0 & 194.1 & 179.8 \\
\hline 40 & 280.3 & 205.6 & 231.8 \\
\hline 50 & 312.0 & 227.0 & 256.6 \\
\hline 60 & 312.0 & 248.4 & 252.7 \\
\hline 70 & 312.0 & 290.9 & 284.4 \\
\hline 80 & 312.0 & 305.3 & 305.4 \\
\hline 90 & 325.9 & 325.9 & 305.4 \\
\hline FBP & 325.9 & 325.9 & 305.4 \\
\hline Biofuel recovered, vol. \% & 80 & 85 & 95 \\
\hline Unconverted, residue and Loss, vol. \% & 20 & 15 & 5 \\
\hline Biofuel yield, wt \% based on feed & 52.14 & 69.915 & 84.1 \\
\hline Biofuel selectivity , \% & 60.64 & 86.73 & 88.37 \\
\hline
\end{tabular}

Table (3) Distribution of the hydrotreated Products Obtained at Various H2 Pressure.Temperature: 450 0C, LHSV. : 5h-1 and H2 / feed: $1600 \mathrm{~L} / \mathrm{L}$

\begin{tabular}{|c|c|c|c|}
\hline Hydrotreated Products & 1.0 MPa & $2.5 \mathrm{MPa}$ & $5.0 \mathrm{Mpa}$ \\
\hline Total conversion, wt \% & 70.75 & 95.23 & 98.15 \\
\hline \multicolumn{4}{|l|}{ Hydrotreated product, Wt \% } \\
\hline Gases & 5.14 & 7.51 & 10.93 \\
\hline Liquid & 94.86 & 92.49 & 89.07 \\
\hline Water content & 3.10 & 3.62 & 3.93 \\
\hline Oil content & 91.76 & 88.87 & 85.14 \\
\hline Density at $20{ }^{\circ} \mathrm{C}$ & 0.8140 & 0.8065 & 0.7959 \\
\hline Kinematic viscosity at $40{ }^{\circ} \mathrm{C}$ & 4.132674 & 3.695354 & 3.358297 \\
\hline Sulpher content, ppm & 0.0052 & 0.0060 & 0.0034 \\
\hline \multicolumn{4}{|l|}{ ASTM distillation, vol. $\% /{ }^{0} \mathrm{C}$} \\
\hline IBP & 60 & 60 & 60 \\
\hline 10 & 160 & 100 & 100 \\
\hline 20 & 250.8 & 155 & 120 \\
\hline 30 & 284.4 & 179.8 & 150 \\
\hline 40 & 305.4 & 231.8 & 199.4 \\
\hline 50 & 305.4 & 256.6 & 231.6 \\
\hline 60 & 305.4 & 252.7 & 250.3 \\
\hline 70 & 305.4 & 284.4 & 284.4 \\
\hline 80 & 325.9 & 305.4 & 284.4 \\
\hline 90 & 325.9 & 305.4 & 305.4 \\
\hline FBP & 325.9 & 305.4 & 305.4 \\
\hline Biofuel recovered, vol. \% & 70 & 95 & 98 \\
\hline Unconverted, residue and Loss, vol. \% & 30 & 5 & 2 \\
\hline Biofuel yield, wt \% based on feed & 62.51 & 84.1 & 83.29 \\
\hline Biofuel selectivity , \% & 88.35 & 88.37 & 84.86 \\
\hline
\end{tabular}




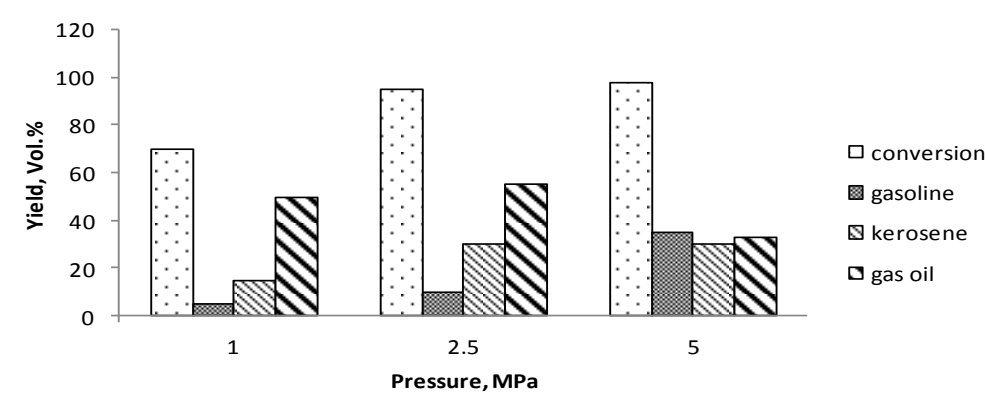

Fig (3) Distribution of the individual fractions of the biofuel obtained as a function of Pressure.

\subsection{Gas chromatography}

The gas chromatographic chart of jojoba oil shows that, the virgin oil composed mainly from heavy straight chain components including more than 16 carbon atoms per molecule, particularly in the range of $\mathrm{C}_{40}-\mathrm{C}_{42}$ (Fig 4a). Most of the raw jojoba oil constitute principally from linear wax esters, the remainder comprises free fatty alcohols and acids. About $70 \%$ of the esters present are combinations of acids and alcohols that are predominantly 20- 22 carbon atoms long. (23)

In contrast, common vegetable oils are supplied as triglycerides that can be seen as the condensation of glycerol and three fatty acids whose carbon chain lengths are mostly 16 and 18 , with varying degree of unsaturation [24]. A comparison between the structure of both jojoba oil and vegetable oils can be illustrated as follows:

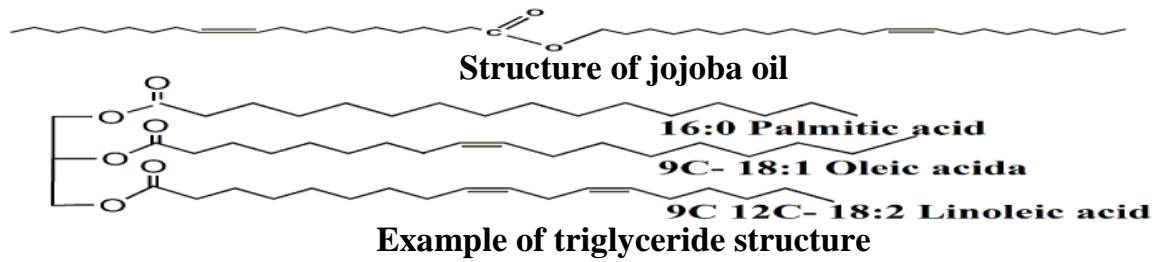

The gas chromatographic spectrum obtained after hydrotreating the crude jojoba oil at $450{ }^{0} \mathrm{C}, 5 \mathrm{~h}^{-1}$ LHSV and 2.5 MPa hydrogen pressure over sulfided $\mathrm{Ni} \mathrm{Mo} / \mathrm{Al}_{2} \mathrm{O}_{3}$ catalyst indicates the disappearance of the peaks corresponding to the high boiling constituents of the feed as declared in Fig (4b).
Instead, the produced oil was enriched with straight chain molecules, most of which posses 20 or 22 carbon atoms that lie in the diesel range. These results are compatible with those attained from the distribution of the distillation range of the product as depicted in Table 3 and Fig (3).
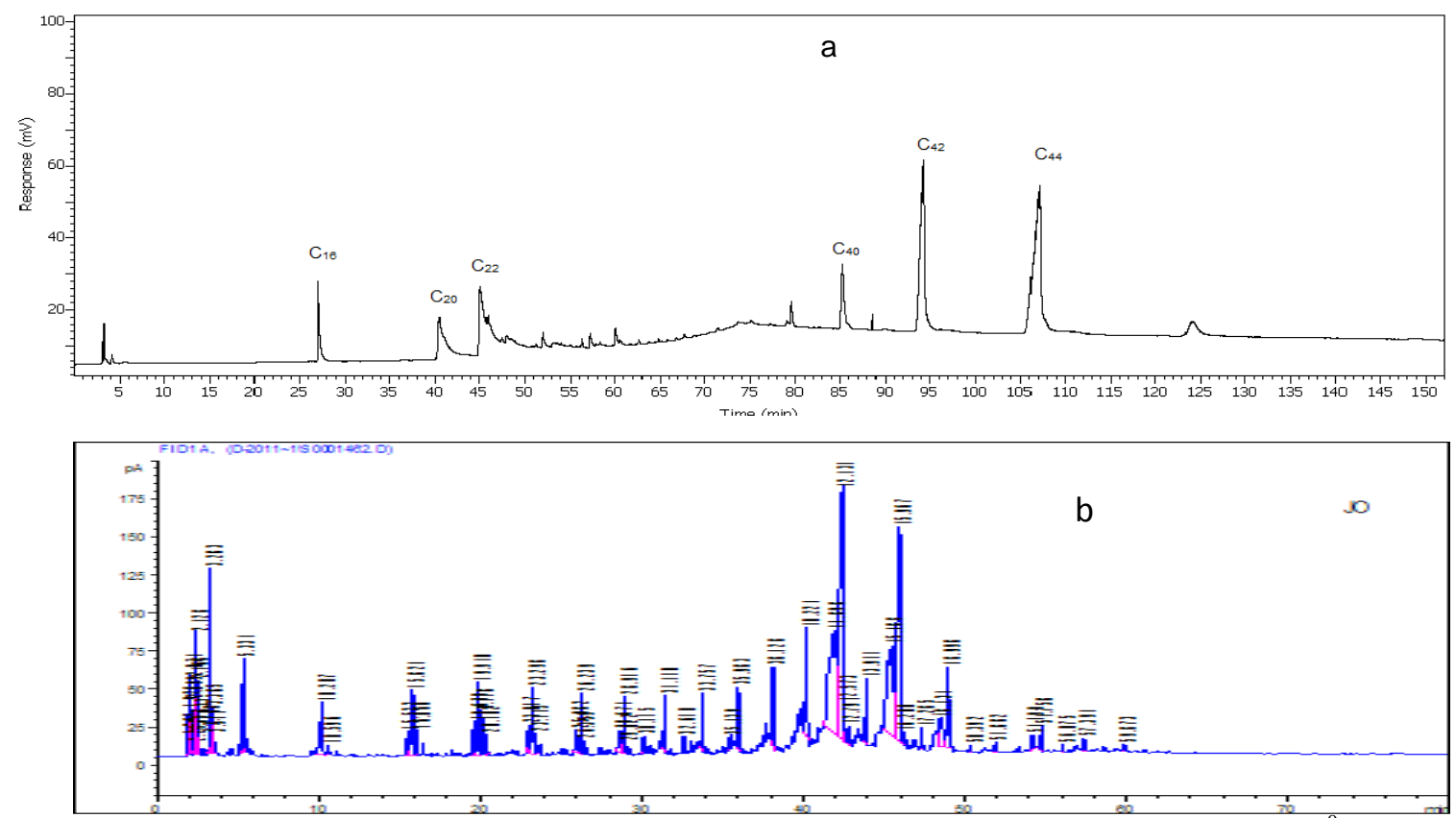

Fig (4) Gas chromatography for (a) Virgin jojoba oil (b) Hydrotreated jojoba oil at $425^{0} \mathrm{C}$. 


\subsection{Forier transform infra red (FTIR) spectroscopy}

The Forier transform infrared spectra of Jojoba oil and the hydrotreated product obtained at $450^{\circ} \mathrm{C}$, 2.5 $\mathrm{MPa}$ and $5 \mathrm{~h}^{-1} \mathrm{LHSV}$ are represented in fig (5) a and $b$. The recorded spectrum of the feed reveals the predomination of aliphatic components as evidenced from the appearance of strong peaks attributed to alkane C-H stretching vibration at $2857-3000 \mathrm{~cm}^{-1}$. Absorption bands were also observed at 1359 and $1457 \mathrm{~cm}^{-1}$ due to aliphatic C-H bending of methyl and methylene groups. Besides the spectrum exhibits a medium absorption peak at $727 \mathrm{~cm}^{-1}$ related to the out-of-plane bends of alkene.

In addition, the IR spectrum reveals noticeable signals in the oxygenated group regions. The intense $\mathrm{C}=\mathrm{O}$ stretching band of ester at $1740 \mathrm{~cm}^{-1}$ and those for stretching vibration of $\mathrm{C}-\mathrm{O}$ at 1150, 1174 and
$1255 \mathrm{~cm}^{-1}$ were detected. Moreover weak bands were also observed at $2676 \mathrm{~cm}^{-1}$ and $3410 \mathrm{~cm}^{-1}$ for $\mathrm{O}-\mathrm{H}$ of carboxylic acid and $\mathrm{H}$ - bonded of alcohol, respectively.

Therefore, the IR analysis characterize the crude jojoba oil as being composed of aliphatic ester, most of which are saturated, and associated with some alcohol and carboxylic functional groups.

Analyzing the spectrum of the hydrotreated jojoba oil (Fig 5b), it could be observed the significant diminution in oxygen content compared with that of the feed (Fig 5a). It is obvious that the characteristic stretching band of $\mathrm{C}=\mathrm{O}$ at $1712 \mathrm{~cm}^{-1}$ has a lower intensity for the obtained product than the corresponding band of crude oil. Also, ratio of the height of this peak and its $\mathrm{CH}_{2}, \mathrm{CH}_{3}$ peak heights at $2857-2925 \mathrm{~cm}^{-1}$ in spectrum $\mathrm{b}$, is lower than that of the virgin oil ( spectrum 5 a ).
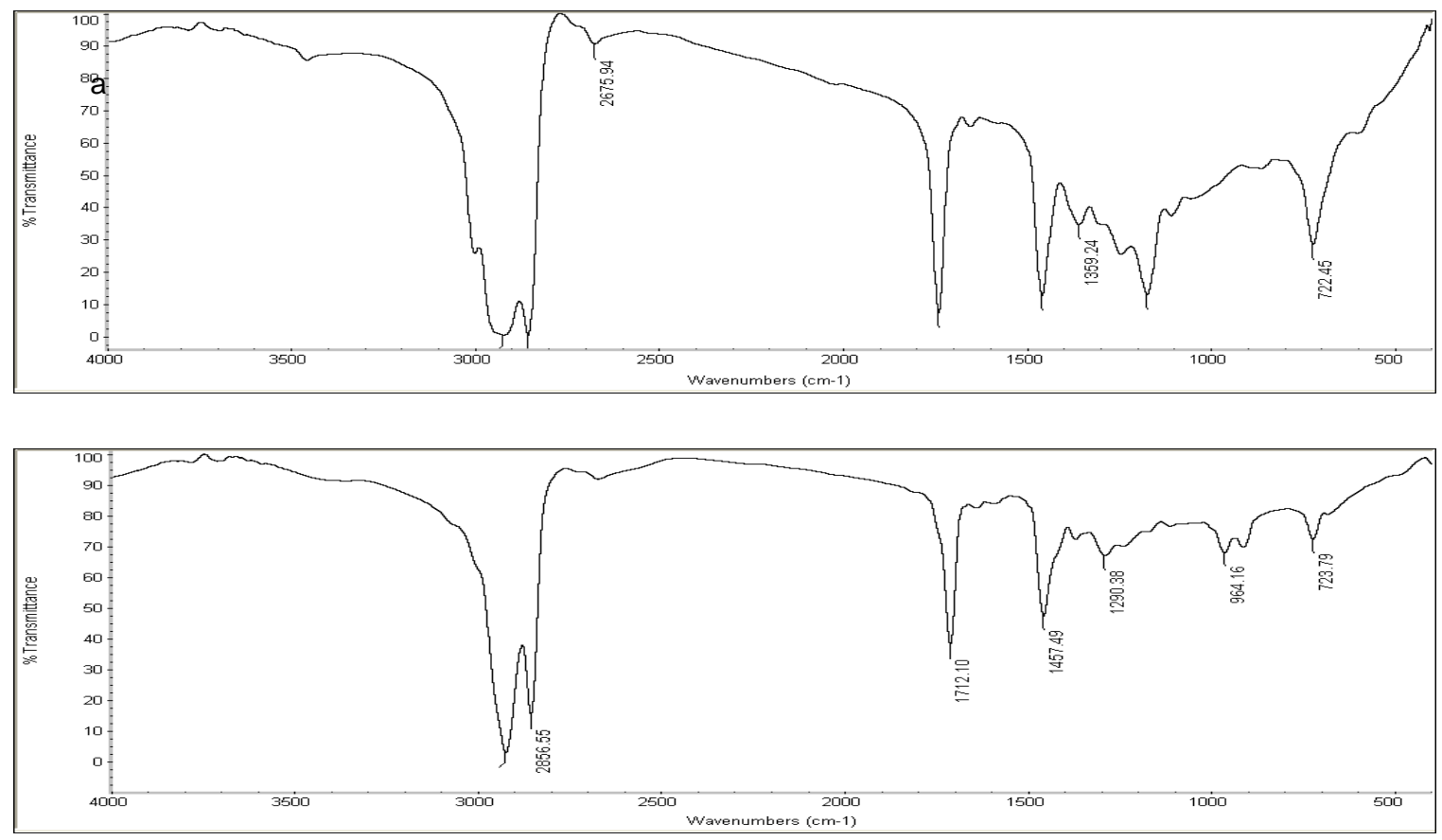

Fig (5) FTIR spectra for (a) Virgin jojoba oil (b) Hydrotreated jojoba oil at $425^{\circ} \mathrm{C}$.

It could be mentioned that the carbonyl group of ester that appeared at $1740 \mathrm{~cm}^{-1}$ in the original spectrum (5a), was shifted in spectrum (5b) to 1712 $\mathrm{cm}^{-1}$ which is characteristic of a ketonic carbonyl group. Furthermore, the medium intensity absorption at 1150,1174 and $1255 \mathrm{~cm}^{-1}$ that related to the stretching vibration of $\mathrm{C}-\mathrm{O}$ shown in spectrum $5 \mathrm{a}$, were significantly reduced in the hydrotreated oil (spectrum $5 \mathrm{~b}$ ). Also the weak band attributed to O$\mathrm{H}$ group that appeared at $2676 \mathrm{~cm}^{-1}$ (spectrum a) was almost vanished in (spectrum b). Therefore the FTIR analysis gave evidences to the clear reduction occurred in the oxygenated content in the hydrotreated oil.

Besides, the hydrotreatment process was accompanied also by partial saturation of the olefinic bonds as revealed from the weakness of the olefin peak at $723 \mathrm{~cm}^{-1}$ ( spectrum b ) comparable with the corresponding peak in( spectrum a).

\subsection{Evaluation of the crude jojoba oil and the hydrotreated product}

The physicochemical properties of the virgin and hydrotreated jojoba oil were evaluated, and the results are depicted in table (4) .

The data reflect the pronounced changes of the characteristics of jojoba oil before and after hydrotreatment at $450^{0} \mathrm{C}, 5 \mathrm{~h}^{-1} \mathrm{LHSV}$ and $2.5 \mathrm{MPa}$ hydrogen pressure. It could be observed that, the applied process succeeded in improving most of the important properties of the oil under investigation to be enabled for usage as a biofuel. For instance, a 
distinct reduction of the density from 0.8650 to 0.8065 as well as an enormous drop in viscosity from 24.9107 to 3.69535 have been occurred. Furthermore, the molecular weight, pour point and refractive index of the attained product were found to be lower than those of the feedstock. Besides, a slight increase in the calorific value of the hydrotreated oil was also achieved, which may be ascribed to the lower value of oxygen of the product with respect to that of the feedstock.

Therefore, these results reveal that, the hydrotreated jojoba oil can be considered as one of the promising and attractive alternative energy from renewable source, in order to meet the great demand of petroleum oil.

Table (4) Physicochemical characteristics of crude and hydrotreated product of jojoba oil

\begin{tabular}{llcc}
\hline Characteristics & \multicolumn{1}{c}{ Method } & Crud jojoba oil & Hydrotreated jojoba oil product \\
\hline Density g/ml at $20{ }^{0} \mathrm{C}$ & ASTM D- 287 & 0.8650 & 0.8065 \\
Kinematic Viscosity , at $40^{\circ} \mathrm{C}$ & ASTM D- 455 & 24.9107 & 3.69535 \\
Sulfur content ,ppm & ASTM D- 4294 & 0.006 & 0.006 \\
Pour point ${ }^{0} \mathrm{C}$ & ASTM D- 97 & 9 & -15 \\
Molecular weight & ASTM D- 2502 & 606 & 211.43 \\
Calorific value, kjol/kgm & ASTM D- 240 & 45121 & 45771 \\
Refractive Index at $20{ }^{0} \mathrm{C}$ & ASTM D- 1747 & 1.442 & 1.42753 \\
Ash content , wt $\%$ & ASTM D- 482 & Nil & Nil \\
Flash point, ${ }^{0} \mathrm{C}$ & ASTM D- 92 & 292 & 92 \\
\hline
\end{tabular}

\section{Conclutions}

Hydrotreating process is found to be a promising technique for producing petroleum-like fractions, particularly biodiesel, from the non-edible jojoba oil, using $\mathrm{NiMo} / \mathrm{Al}_{2} \mathrm{O}_{3}$ catalyst.

The influence of operating variables has been investigated to elucidate the optimum conditions for attainment the maximum yield of the desired biofuel product.

The total conversion of the feedstock is significantly high at all conditions under investigation, except with that performed at $350^{\circ} \mathrm{C}$ and $1 \mathrm{MPa}$ hydrogen pressure. However the distributions of the obtained yields are qualitatively and quantitatively depend on the applied operating variables.

Sufficient high reaction temperature, pressure and liquid hourly space velocity are favorable for the biofuel production, and vice versa. Furthermore, at such conditions, the hydrotreating process leads to a substantial decrease of both density and kinematic viscosity of jojoba oil to reach the required values.

From the obtained data, it could be concluded that the optimum operating conditions for attainment the highest yield of biofuel, comprised $84.1 \mathrm{wt} \%$ with a selectivity of $88.37 \%$ are $450^{\circ} \mathrm{C}, 5 \mathrm{~h}^{-1} \mathrm{LHSV}$ and 2.5 MPa hydrogen pressure.

The acquired biofuel at these circumstances composed from 10 vol\% gasoline, 30 vol\% kerosene and $55 \mathrm{vol} \%$ gas oil, from the obtained liquid oil. The rest represents the loses and unconverted oil

The achieved petroleum-like fractions constitute principally from alkanes, as evidenced from the IR spectrum that indicated the considerable elimination of oxygen from jojoba molecules

After applying the hydrotreating process, a great improvement of the physicochemical characteristics of jojoba oil has been realized in an effort to be used as a renewable fuel alternative to petroleum oil.

\section{References}

[1] P.Kumar, D.M.Barrett, M.J.Delwiche, and P. Stroeve. Methods for pretreatment of lignocellulosic biomass for efficient hydrolysis and biofuel production. Ind. Eng. Chem. Res. Vol.48, pp.3713-3729, 2009.

[2] P.D.Patil, V.G. Gude and S.Deny.Biodiesel production from jatropha curcas, waste cooking and camelina stiva oils. Ind.Eng. Chem.Res. vol.48 (24), pp.10850-10856, 2009.

[3] A.S.Huzayyin, A.H.Badawy, M.A.Rady and A.Dawood. Experimental evaluation of diesel engine performance and emission using blends of jojoba oil and diesel fuel. Energy Conversion and Management. Vol.45, pp.2093-211, 2004.

[4] G.w.Huber, P.Oconnor and A.Corma. Processing biomass in conventional oil refineries: Production of high quality diesel by hydrotreating vegetable oil in heavy vacuum oil mixtures. Applied catalysis A: General. Vol.329, pp.120-129, 2007.

[5] G.Vicente, M.Martinez, and J.Aracil. A comparative study of vegetable oils in biodiesel production in spain. Energy and Fuels. Vol.20, pp.394-398, 2006.

[6] S.Pinzi, I.L.Garcia, F.J.Lopez-Gimenez, M.D.Luque de Castro, G. Dorado and M.P. Dorado. The ideal vegetable oil- based biodiesel composition: A review of social, economical and technical implications. Energy \& Fuels. Vol.23 (5), pp.2325-2341, 2009.

[7] M.Lapuerta, J.R.Fernandez, F.Oliva and L.Canoiva . Biodiesel from low - grade animal 
fats: Diesel engine performance and emissions. Energy\& Fuels. Vol.23(1), pp.121-129, 2009.

[8] L.Canoira, M.Rodriguez-Gamero, E.Querol, R.Alcantara, M.Lapuerta and F.Oliva, Biodiesel from Low-Grade Animal Fat: production process Assessment and biodiesel properties characterization. Ind. Eng. Chem. Res. Vol.27. pp.7997-8004, 2008.

[9] J.Hancsok, M.Krar, S.Magyar, L.Boda, A.Hollo, and D.Kallo. Investigation of production of high cetan number biogas oil from pre- hydrogenated vegetable oils over pt/ HZSM. 22/ $\mathrm{Al}_{2} \mathrm{O}_{3}$. Microporous and Mesoporous Materials, vol.101, pp.148-152, 2007.

[10] P.Priecel, L.Capek, D.Kubicka, F.Homola, P.Rysanek and M.Pauzar. The role of alumina support in the deoxygenation of rapeseed oil over NiMo-alumina catalysts. Catalysis Today. Vol.176, pp.409-412, 2011.

[11] A.F.Twaig, A.M.Zabidi and S.Bhatia. Catalytic conversion of palm oil to hydrocarbons performance of various zeolite catalysts. Ind. Eng. Chem. Res. Vol.38, p.3230-3237, 1999.

[12] J.Mikulec, J.Cvengros, L.Jorikova, M.Banic, and A.Kleinova. Production of diesel fuels from waste triacylglycerols by hydrodeoxygenation. $44^{\text {th }}$ International petrolume confrance, Bratislava, Slovak Republic , September 21-22 2009.

[13] R.Sarin, M.Sharma, S.Sinharay and R.K.Malhorta. Jatropha - palm biodiesel blends: An optimum mix for asia. Fuel. Vol.86. pp.13651371, 2007.

[14] N.Ravindanath, B.Venkataiah, C.Ramesh, P.Jayaprakash, and B.Das. Jatrophenon a novel macrocyclic bioactive diterpene from jatropha gossypifolia. Chem. Phrm. Bull vol.51, pp.870, 2003.

[15] S.Einloft, T.O.Magalhaes, A.Donato, J.Dullius and R.Ligabue. Biodiesel from rice bran oil: Transesterification by tin compounds. Energy \& Fuels. Vol.22, pp.671-674, 2008.
[16] G.Knothe, S.C.Cermak and R.L.Evangelista. Cuphea oil as source of biodiesel with improved fuel properties caused by high content of methyl decanoate. Energy \& Fuels, vol.23. pp.1743:1747, 2009.

[17] N.N.Mahamuni and Y.G.Adewuyi. Optimization of the synthesis of biodiesel via ultrasound - enhanced base- catalyzed transesterification of soybean oil using a multifrequency ultrasonic reactor. Energy \& Fuels. Vol.23, pp.2757- 2766, 2009.

[18] L.Canoira, R.Alcantara, M.J.Garcia-Martinez and J.Carrasco. Biodiesel from Jojoba oil-wax: Transesterification with methanol and properties as a fuel. Biomass and Bioenergy, vol.30, pp.7681, 2006.

[19] Y.Ooi, R.Zakaria, A.Mohamed and S.Bhatia. Catalytic conversion of palm oil - based fatty acid mixture to liquid fuel . Biomass and Bioenergy. Vol.27, pp.477- 484(a), 2004.

[20] Y.Ooi, R.Zakaria, A.Mohamed and S.Bhatia. Catalytic cracking of used palm oil and palm oil fatty acids mixture for the production of liquid fuel: Kinetic modeling. Energy \& Fuels. Vol.18, pp.1555 - 1561(b), 2004.

[21] ,K.Belkacemi and S.Hamoudi. Law trans and saturated vegetable oil hydrogenation over nanostructured $\mathrm{Pd} /$ silica catalysts : Process parameters and mass- transfer features effects. Ind. Eng .Chem. Res. Vol.48, pp.1081-1089, 2009.

[22] L.K.Mohamed, Study on catalytic reforming reactions using unconventional catalysts. $\mathrm{PhD}$ thesis, Faculty of Engineering, Cairo university . p.46, 2000.

[23] M.K EL- Bahr. Jojoba : New crop for arid lands , New raw material for industry, National academy press, p.38, 2002.

[24] R.Egeberg, N.Michaelen L.Shyum and P.Zeuthen. Hydrotreating in the production of green diesel. PTQ 02 .102, 2010. 